Research Paper

\title{
Dermatophytosis diagnosed at the Evandro Chagas Institute, Pará, Brazil
}

\author{
Fabíola Silveira-Gomes ${ }^{1}$, Elaina Ferreira de Oliveira $^{2}$, Lívia Barreto Nepomuceno ${ }^{2}$, \\ Rosiane Ferreira Pimentel ${ }^{2}$, Silvia Helena Marques-da-Silva ${ }^{2}$, \\ Maurimélia Mesquita-da-Costa ${ }^{2}$ \\ ${ }^{1}$ Instituto de Ciências Biológicas, Universidade Federal do Pará, Belém, PA, Brazil. \\ ${ }^{2}$ Laboratório de Micologia, Seção de Bacteriologia e Micologia, Instituto Evandro Chagas, \\ Ananindeua, PA, Brazil.
}

Submitted: April 28, 2011; Approved: June 05, 2012.

\begin{abstract}
Dermatophytosis is caused by a dermatophyte fungus that affects the stratum corneum and keratinized tissue. Dermatophyte fungus has been reported worldwide as the causative agent of dermatophytosis, but the etio-epidemiological aspects of these mycoses in the state of Pará remain unknown. The purpose of this study was to describe the etio-epidemiological profile of dermatophytosis diagnosed in patients at the Evandro Chagas Institute from May 2005 to June 2006. A total of 494 patients were admitted, and their samples were collected, submitted for direct microscopic examination using $20 \% \mathrm{KOH}$ and cultured in Sabouraud and Mycosel medium. The identification was based in macro and microscopic characteristics. Direct examinations were positive in 13\% (66/494) of the patients, and agent isolation by cultivation of the biological sample was successful in $4 \%$ (20/494), with a high prevalence of $T$. mentagrophytes $(40 \% ; 8 / 20)$. Dermatophytosis was more frequent in women $(58 \% ; 38 / 66)$. Fifty-two percent $(21 / 38)$ of the cases were children with an average age of 8 years. The most frequent clinical presentation was Tinea corporis $(55 \%, 36 / 66)$. For the cases in which the dermatophyte agent was not isolated, we discuss the factors that may be interfering with isolation. Tinea corporis occurred more frequently observed when T. mentagrophytes and T. rubrum were the major etiologic agents.
\end{abstract}

Key words: dermatophytosis, etio-epidemiology, Trichophyton, T. mentagrophytes.

\section{Introduction}

Dermatophytosis is the colonization of the keratinized tissues (nails, hair, and stratum corneum of the skin) by a dermatophytic fungus. Members of the following three anamorphic genera can cause the infection: Trichophyton, Microsporum, and Epidermophyton, each of which has related morphological, physiological and antigenic characteristics (Weitzman and Summerbell, 1995). They are distributed worldwide and may be categorized as geophilic, zoophilic and anthropophilic fungi (Aly, 1994), and it is suggested that zoophilic fungi can cause more of an inflammatory reaction than anthropophilic fungi (Wagner and Sohnle, 1995). The development of disease is a consequence of the host reaction to the fungal metabolic products rather than to the invasion of living tissue by the microorganism. The symptoms induced in the host are initially an eczema-like response, followed by an inflammatory manifestation (Zurita and Hay, 1987). The clinical manifestations and the infection severity are related to the causative strain and species, as well as to the immune state of the host (Duek et al., 2004). Degreef (2008) identified seven clinical presentations: Tinea corporis, Tinea cruris, Tinea faciei, Tinea pedis, Tinea manus, Tinea capitis, and Tinea barbae.

Dermatophytosis is the most common skin infection in the world (Diaz et al., 1984). The use of antimicrobial, immunosuppressive and cytostatic drugs, as well as the emergence of AIDS, has been reported as a source of the increased incidence of dermatophytoses (Greer, 1994). In

Send correspondence to M.M. Costa. Laboratório de Micologia, Seção de Bacteriologia e Micologia, Instituto Evandro Chagas, Rodovia BR 316 , km 7 s/n, Levilândia, Ananindeua, PA, Brasil. E-mail: maurimesq@gmail.com. 
Brazil, because dermatophytoses are not reportable diseases, only fragmented reports have been published in some states. For example, Aquino et al. (2003) reported an elevated occurrence of Tinea capitis (82 cases) in João Pessoa (northeast Brazil) from October 1999 to February 2000. Of these cases, T. rubrum was the most frequently isolated dermatophyte. These data corroborate results from São Paulo (southeast Brazil), where the major etiologic agent isolated was T. rubrum in a study over a period of ten years (Chinelli et al., 2003). In Fortaleza, Ceará state (northeast Brazil), this species is the most frequently isolated, except for cases of Tinea capitis (scalp lesions) where the directly related dermatophyte is $T$. tonsurans (Brilhante et al., 2000). Data from west-central Brazil show a slight predominance of $T$. rubrum followed by $T$. mentagrophytes; in these data, the majority of cases were lesions on the feet (Costa et al., 1999). Finally, in the state of Paraná (south Brazil), the main agent causing onychomycosis and Tinea pedis is T. mentagrophytes (Purim et al., 2009). Although data have been reported from other regions of the country, no studies from the north region of Brazil have commented on any aspects related to dermatophytosis.

The aim of the present work was to describe the eti-oepidemiological profile of dermatophytoses diagnosed at the Evandro Chagas Institute (Belém, Pará, Brazil).

\section{Materials and Methods}

\section{Patients}

A total of 494 individuals with lesions of the nails, hair, and skin suggestive of dermatophytosis were included in the study. The specimens were collected from May 2005 to June 2006 at the Evandro Chagas Institute. The study was conducted according to the ethical committee on human experimentation (Evandro Chagas Institute), and the patients selected were informed about the study and signed informed consent prior to participating.

\section{Laboratory methods}

The clinical specimens were collected (plucked hair/scraped scales) on slides or in Petri plates and examined for the presence of fungal elements. Slides were flooded with $20 \%$ potassium hydroxide $(\mathrm{KOH})$ and observed under a light microscope (Carl Zeiss) at a 40X magnification. A dermatophytosis was considered to be present based on the finding of arthroconidia derived from hyaline hyphae. All samples were cultured both on Sabouraud agar and Mycosel medium (Difco, Detroit, Mich.), incubated at room temperature $\left(25^{\circ} \mathrm{C}\right)$ for two weeks or more, and examined daily. The identification of dermatophytes was based on the macroscopic and microscopic characteristics of the colonies grown on the culture medium. To identify the fungus at the species level, microcultures (Sidrim and Moreira, 1999) of the dermatophytes were carried out in
Potato Dextrose agar (Difco, Detroit, Mich.) maintained at $25{ }^{\circ} \mathrm{C}$, followed by microscopic examination of the slides stained with lactophenol cotton blue to observe micromorphological characteristics of the species according to De Hoog (2000).

\section{Statistical analysis}

The statistical analysis was performed using the software BioEstat version 5.0. The $\chi^{2}$ test was performed to determine whether there was a statistically significant difference among the sampled groups. Differences of $p<0.05$ were considered significant.

\section{Results}

A total of 494 patients were included, but only $13 \%$ (64/494) were positive upon direct examination; these cases included five different types of clinical presentations (Table 1). Two cases of Tinea capitis were negative on mycological direct examination but had positive cultures. In four cases, co-infection by yeasts of the genus Malassezia was observed. Of the positive results, $42 \%(28 / 66)$ were male and 52\% (38/66) female. A disproportionate number of cases $(52 \% ; 38 / 66)$ occurred in children of preschool and school age (Table 2), with a mean age of 8 years.

The causative agent was isolated in $4 \%(20 / 494)$ of the cases, and the following species were identified: $T$.

Table 1 - Clinical presentation according to the sex of the patients with result positive from dermatophytosis.

\begin{tabular}{lccc}
\hline \multirow{2}{*}{ Clinical presentation } & \multicolumn{2}{c}{ Sex } & \multirow{2}{*}{ Total } \\
\cline { 2 - 3 } & Male & Female & \\
\hline Tinea corporis & 9 & 12 & 21 \\
Tinea capitis $*$ & 6 & 15 & 21 \\
Tinea unguium & 5 & 5 & 10 \\
Tinea pedis & 4 & 4 & 8 \\
Tinea cruris & 4 & 2 & 6 \\
Total & 28 & 38 & 66 \\
\hline
\end{tabular}

*Two cases were negative in direct examination, but positive on culture.

Table 2 - Distribution of cases according to age and sex.

\begin{tabular}{lccc}
\hline Age & \multicolumn{2}{c}{ Sex } & \multirow{2}{*}{ Total } \\
\cline { 2 - 3 } & Male & Female & \\
\hline Preschool and school & & & \\
0-11 months & 2 & 1 & 3 \\
1-10 years & 5 & 12 & 17 \\
11-20 years & 5 & 9 & 14 \\
Adults & & & \\
$>$ 20 years & 16 & 16 & 32 \\
Total & 28 & 38 & 66 \\
\hline
\end{tabular}


mentagrophytes (8), T. rubrum (6), T. tonsurans (2), T. verrucosum (1), M. gypseum (1), M. canis (1), and E. floccosum (1). T. mentagrophytes was more often isolated from cases of Tinea capitis, whereas T. rubrum was isolated from three different clinical presentations (Tinea corporis, Tinea cruris, and Tinea pedis). T. tonsurans, T. verrucosum, $M$. gypseum, $M$. canis and $E$. floccosum were isolated from Tinea capitis, Tinea corporis and Tinea pedis (Table 3).

In five cases, we found the presence of other fungal species as contamination or as a co-infecting agent: Candida parapsilosis (2), Candida tropicalis (1), Trichosporon asahii (2) and Trichosporon inkii (1). In one of these cases, two additional agents were isolated. All species were identified by API ID 32C (bioMerieux, France). In the majority of the other cases, either growth of dermatophyte or contamination by bacterial colonies was observed. Bacterial species were not identified.

Only 24\% (16/66) of the patients had contact with animals, such as dogs and cats. However, it is possible that this contact as the source of the contagion in one case only (M. canis). In the cases in which the causative agent was not isolated, 39\% (18/46) of the patients reported previous use of an antifungal drug. Ketoconazole $(72 \% ; 13 / 18)$ was the most commonly reported drug, followed by miconazole $(28 \% ; 5 / 18)$. Although the use of antifungals has been re-

Table 3 - Dermatophyte identification of 20 cases studied with positive isolation.

\begin{tabular}{|c|c|c|c|}
\hline Causative specie & $\begin{array}{l}\text { Patient } \\
\text { register } \mathrm{n}^{\mathrm{o}}\end{array}$ & Site & Type of Tinea \\
\hline T. mentagrophytes & 144 & Skin (thorax) & Tinea corporis \\
\hline T. mentagrophytes & 300 & Scalp & Tinea capitis \\
\hline T. mentagrophytes & 342 & Scalp & Tinea capitis \\
\hline T. mentagrophytes & 360 & Scalp & Tinea capitis \\
\hline T. mentagrophytes & 143 & Scalp & Tinea capitis \\
\hline T. mentagrophytes & 352 & Scalp & Tinea capitis \\
\hline T. mentagrophytes & 190 & Scalp & Tinea capitis \\
\hline T. mentagrophytes & 203 & Nail & Tinea unguium \\
\hline T. rubrum & 188 & Foot & Tinea pedis \\
\hline T. rubrum & 237 & Glutea region & Tinea cruris \\
\hline T. rubrum & 293 & Inguinal region & Tinea cruris \\
\hline T. rubrum & 304 & Skin (thorax) & Tinea corporis \\
\hline T. rubrum & 07 & Glutea region & Tinea cruris \\
\hline T. rubrum & 78 & $\begin{array}{l}\text { Skin (inferior } \\
\text { member) }\end{array}$ & Tinea corporis \\
\hline T. tonsurans & 51 & Scalp & Tinea capitis \\
\hline T. tonsurans & 11 & Scalp & Tinea capitis \\
\hline T. verrucosum & 46 & Scalp & Tinea capitis \\
\hline M. canis & 127 & Scalp & Tinea capitis \\
\hline M. gypseum & 331 & Foot & Tinea pedis \\
\hline E. floccosum & 167 & Skin (thorax) & Tinea corporis \\
\hline
\end{tabular}

ported, this variable cannot be directly related as a factor whose absence influenced the isolation of the dermatophyte $(\mathrm{p}>0.05)$ (Table 4$)$.

\section{Discussion}

According to our results, direct microscopic examination was more sensitive than was fungal culture. For example, only $30.3 \%(20 / 66)$ of the dermatophytosis cases were positive on culture. However, although direct examination allows an immediate diagnosis, more accurate results are obtained following fungal culture. The failure to isolate dermatophytes may have been the result of secondary agents, such as yeast and skin bacteria, that are not inhibited by chloramphenicol/cycloheximide.

Over a period of approximately one year of collection and isolation, seven dermatophyte species were detected as dermatophytosis agents in Pará state: T. mentagrophytes, $T$. rubrum, T. tonsurans, T. verrucosum, M. gypseum, $M$. canis, and E. floccosum. The predominance of $T$. mentagrophytes is not consistent with data reported in studies from other regions of Brazil (Campbell et al., 1984; Costa et al., 1999; Cucé et al., 1975), given that this species was an important cause of Tinea capitis in this study. In contrast, other regions of world indicate T. mentagrophytes as the third most common etiologic agent in this clinical presentation of dermatophytosis (Sidat et al., 2007). In Brazil, T. rubrum is the most commonly isolated species, typically in Tinea capitis or Tinea corporis cases from patients of any age group (Bergson and Fernandes, 2001; Lima et at., 1999; Lopes et al., 1994).

An important result observed with direct examination for diagnosis was increased incidence in preschool/schoolaged children. In Brazil, the occurrence of Tinea capitis was described as the major clinical presentation of infection by dermatophytes in this age group, but the main previously reported causative agent was $M$. canis (Fernandes et al., 2001). In this study, one case of Tinea capitis was shown to be due to $M$. canis directly linked to contact with a dog according to the patient's father, who reported that the child had his hair combed with a brush that was frequently used on a dog. Domestic animals such as cats and dogs are well-known likely sources of dermatophytoses in urban areas (Pinheiro and Moreira, 1997). Because we could not determine the variety of $T$. mentagrophytes species, we do not

Table 4 - Description of the use of antifungal drug before the mycological examination and its influence in the isolation of the dermatophyte.

\begin{tabular}{lccc}
\hline \multirow{2}{*}{ Use of antifungal } & \multicolumn{2}{c}{ Isolation of dermatophyte } & \multirow{2}{*}{ Total } \\
\cline { 2 - 3 } & Yes & No & \\
\hline Yes & 10 & 21 & 31 \\
No & 10 & 25 & 35 \\
Total & 20 & 46 & 66 \\
\hline
\end{tabular}

$\chi^{2}=0.106 ; \mathrm{p}=0.7450$. 
comment on the different dermatophyte categories (geophilic, zoophilic or anthropophilic). Although our results demonstrate a predominance of anthropophilic dermatophytes, other categories were also detected.

In summary, our results demonstrate $T$. mentagrophytes followed by T. rubrum as the most important dermatophytes and the most frequent isolates in patients with Tinea capitis, Tinea corporis and Tinea curis in this region of Brazil.

\section{References}

Aly R (1994) Ecology and epidemiology of dermatophyte infections. J Amer Acad Derm 31:521-525.

Aquino PMLP, Lima EO, Farias NMP (2003). Tinea Capitis in João Pessoa: A social and economic view. An Bras Dermatol 78:713-717.

Bergson CL, Fernandes NC (2001) Tinea capitis: Estudo de portadores assintomáticos e doentes adolescentes, adultos e idosos coabitantes com crianças com a infecção. Rev Inst Med Trop 43:87-91.

Brilhante RSN, Paixão GC, Salvino LK, Diógenes MJN, Bandeira SP, Rocha MFG, Santos JBF, Sidrim JJC (2000) Epidemiology and ecology of dermatophytosis in fortaleza city: Trichophyton tonsurans as an important emergent pathogen of Tinea capitis. Rev Soc Bras Med Trop 33:417-425.

Campbell I, Campbell G, Aguirre L, Santos MG (1984) Dermatófitos em Brasilia. An Bras Derm 59:224-225.

Chinelli PAV, Sofiatti AA, Nunes RS, Martins JEC (2003) Dermatophyte agents in the city of São Paulo, from 1992 to 2002. Rev Inst Med Trop S Paulo 45:259-263.

Costa TR, Costa MR, Silva MV, Rodrigues AB, Fernandes OFL, Soares AJ et al. (1999) Etiology and epidemiology in dermatophytosis in Goiânia, State of Goiás, Brazil. Rev Soc Bras Med Trop 32:367-371.

Cucé LC, Castro RM, Dinato SLM, Salebian A (1975) Flora dermatofítica em São Paulo (1964-1974). An Bras Derm 50:141-146.

de Hoog GS, Guarro J, Gené J, Figueras MJ (2000). Atlas of Clinical Fungi (2nd ed). Centraalbureau voor Schimmelcultures Universitat Rovira i Virgilli.
Degreef H (2008) Clinical Forms of Dermatophytosis (Ringworm Infection). Mycopathologia 166:257-265.

Diaz MC, Salamanca L, Piontelli E (1984) Dermatofitosis: Um problema del passado, un desafio del presente. Adel Microbiol Enferm Inf 3:212-273.

Duek L, Kaufman G, Ulman Y, Berdicevsky I (2004) The pathogenesis of dermatophyte infections in human skin sections. $J$ Infect 48:175-180.

Fernandes NC, Akiti T, Barreiros MGC (2001) Dermatophytoses in children: Study of 137 cases. Rev Inst Med Trop 43:8385.

Greer DL (1994) An overview of commom dermatophytes. J Am Acad Dermatol 31:112-116.

Lima EO, Oliveira NMC, Guerra MFL, Pontes ZBVS, Carvalho MFFP, Santos JP (1999) Freqüência de dermatofitoses em João Pessoa - Paraíba - Brasil. An Bras Derm 74:127-132.

Lopes JO, Alves SH, Benevenga JP (1994) Dermatofitoses humanas no interior do Rio Grande do Sul no período 1998-1992. Rev Inst Med Trop 14:115-119.

Purim KSM, Freitas CFNP, Leite N (2009) Feet dermatophytosis in Soccer Players. An Bras Dermatol 84:550-552.

Pinheiro AQ, Moreira JLB, Sidrim JJC (1997) Dermatofitoses no meio urbano e a coexistência do homem com cães e gatos. Rev Soc Bras Med Trop 30:287-294.

Sidat MM, Correia D, Buene TP (2007) Tinea capitis among children at one suburban primary school in the City of Maputo, Mozambique. Rev Inst Med trop 40:473-475.

Sidrim JJC, Moreira JLB (1999) Fundamentos Clínicos e Laboratoriais da Micologia Médica. Editora Guanabara Koogan, São Paulo, 287 pp.

Wagner DK, Sohnle PG (1995) Cutaneous defenses against dermatophytes and yeasts. Clin Microbiol Rev 8:317-335.

Weitzman I, Summerbell RC (1995) The dermatophytes. Clin Microbiol Rev 8:240-259.

Zurita J, Hay RJ (1987) Adherence of dermatophyte microconidia and arthroconidia to human keratinocytes in vitro. J Invest Dermatol 89:529-534.

All the content of the journal, except where otherwise noted, is licensed under a Creative Commons License CC BY-NC. 